\title{
North Atlantic humpback whale abundance and rate of increase four decades after protection from whaling
}

\author{
Peter T. Stevick ${ }^{1,11, *}$, Judith Allen ${ }^{2}$, Phillip J. Clapham ${ }^{3}$, Nancy Friday ${ }^{4}$, \\ Steven K. Katona ${ }^{2}$, Finn Larsen ${ }^{5,12}$, Jon Lien ${ }^{6}$, David K. Mattila ${ }^{7}$, Per J. Palsbøll ${ }^{8,13}$, \\ Jóhann Sigurjónsson ${ }^{9}$, Tim D. Smith ${ }^{3}$, Nils Øien ${ }^{10}{ }$, Philip S. Hammond ${ }^{1}$ \\ ${ }^{1}$ Sea Mammal Research Unit, Gatty Marine Laboratory, University of St Andrews, Fife KY16 8LB, Scotland \\ ${ }^{2}$ College of the Atlantic, 105 Eden Street, Bar Harbor, Maine 04609, USA \\ ${ }^{3}$ Northeast Fisheries Science Center, 166 Water Street, Woods Hole, Massachusetts 02543-1026, USA \\ ${ }^{4}$ Cetacean Assessment and Ecology Program, National Marine Mammal Laboratory, AFSC/NMFS, Seattle, Washington 98115-6349, USA \\ ${ }^{5}$ Greenland Institute for Natural Resources, PO Box 570, 3900 Nuuk, Greenland \\ ${ }^{6}$ Biopsychology Programme and Ocean Sciences Centre, Memorial University of Newfoundland, St. Johns A1C 5S7, Canada \\ ${ }^{7}$ Center for Coastal Studies, PO Box 1036, Provincetown, Massachusetts 02657, USA \\ ${ }^{8}$ Department of Population Biology, University of Copenhagen, 2100 Copenhagen Ø, Denmark \\ ${ }^{9}$ Marine Research Institute, Skulagata 4, PO Box 1390, 121 Reykjavik, Iceland \\ ${ }^{10}$ Institute of Marine Research, PO Box 1870, Nordnes, 5817 Bergen, Norway \\ ${ }^{11}$ Present address: PO Box 93, Rockport, Maine 04856-0093, USA \\ ${ }^{12}$ Present address: Danish Institute for Fisheries Research, Charlottenlund Castle, 2920 Charlottenlund, Denmark \\ ${ }^{13}$ Present address: University of California at Berkeley, Ecosystem Sciences Division - ESPM, California 94720-3110, USA
}

\begin{abstract}
Humpback whales Megaptera novaeangliae in the North Atlantic Ocean were severely depleted by exploitation. With legal protection since 1955, substantial recovery is likely to have occurred, but information on abundance and rates of increase has been limited. We present an assessment of humpback whale abundance in the North Atlantic Ocean based upon capturerecapture estimates using naturally marked individuals. These data result from a long-term collaborative effort combining large-scale dedicated projects and incidental data collection, leading to extensive geographical coverage. The application of robust statistical techniques produces estimates of greater accuracy and precision than has previously been possible. Abundance estimates ranging from 5930 to 12580 individuals, with coefficients of variation (CVs) from 0.07 to 0.39 , were calculated for the West Indies breeding population using data from 1979 to 1993. The most precise estimate for the West Indies breeding population is 10752 (CV = 0.068) for 1992 and 1993. Due to application of new analytical methods, these estimates are larger and more precise than those previously published from similar time periods. The average rate of increase for the West Indies breeding population over a $14 \mathrm{yr}$ period was estimated to be $0.031(\mathrm{SE}=0.005)$. The best available estimate for the entire North Atlantic population of humpback whales is 11570 (95\% CI 10290 to 13 390) based upon samples from 1992 and 1993. However, this estimate may be biased downwards to an unknown extent due to heterogeneity in capture probabilities that do not influence the West Indies estimates.
\end{abstract}

KEY WORDS: Abundance estimation $\cdot$ Population increase $\cdot$ Humpback whale $\cdot$ Capture-recapture

\section{INTRODUCTION}

Humpback whales Megaptera novaeangliae were an early target of the modern pelagic whaling industry, and were one of the predominant species taken between the 1860s and the early decades of the 1900s. High levels of hunting mortality led to rapid declines in abundance; in most areas, stocks were severely depleted within a few years of the advent of commercial operations (Tønnessen \& Johnsen 1982). Commer- 
cial hunting was banned by the International Whaling Commission in the North Atlantic in 1955, in the Southern Hemisphere in 1963 to 1964 and in the North Pacific in 1966 (Mackintosh 1965, Best 1993). Humpback whales are listed as endangered under the United States Endangered Species Act of 1973 (NMFS 1991) and as vulnerable by the World Conservation Union (IUCN 2000).

In the North Atlantic Ocean, humpback whales were hunted in all areas where substantial concentrations occur (Fig. 1). Major high-latitude summer feeding areas are located in the Gulf of Maine, in coastal waters of eastern Canada, off West Greenland, near Iceland and Jan Mayen, and from coastal Norway into the Barents Sea. The largest winter breeding and calving aggregation occurs in the West Indies. In recent decades this has principally centered north of the Greater Antilles. Individuals were hunted in other areas in winter, notably in the eastern Caribbean and near the Cape Verde Islands.
Humpback whales have been taken in the North Atlantic since at least the 17th century (Smith \& Reeves 2003b). A combination of non-mechanized pelagic whaling and small-scale coastal operations took over 2000 humpback whales during the 19th century (Smith \& Reeves 2003a). Between 1885 and 1910, nearly 5000 individuals were taken by early modern whaling operations off Norway and Iceland (Ingebrigtsen 1929, Sigurjónsson 1988, Smith \& Reeves 2003b), and also from other parts of northern Europe (Thompson 1928, Tønnessen \& Johnsen 1982). These large catches almost completely exterminated humpbacks from the eastern North Atlantic, and whalers turned to other species or other waters when they were unable to find humpbacks (Tønnessen \& Johnsen 1982). In Canadian Atlantic waters they were depleted by the 1920 s, with an estimated take of about 1600 between 1895 and 1930 (Tønnessen \& Johnsen 1982, Smith \& Reeves 2003b). Takes continued in some areas until commercial hunting was banned in 1955 (Smith \& Reeves 2003b), while small subsistence takes continued in Greenland until 1985 and are ongoing in St. Vincent and the Grenadines (Smith \& Reeves 2003b). For recent reviews of catch data see Reeves \& Smith (2002), and Smith \& Reeves (2002, 2003a,b).

Population recovery has been difficult to document. Humpback whales are long-lived, have relatively low reproductive capacity, are widely distributed, and capable of large-scale movements. Thus assessment of abundance trends requires a long time series of data over broad geographic areas. In some populations, high rates of increase have been reported (e.g. Bannister 1994, Paterson et al. 2001), while in others there is little evidence of recovery (e.g. Moore et al. 1999).

In the North Atlantic, few data are available to substantiate or quantify the extent of population recovery since the end of commercial hunting. Some regional estimates suggest that abundance is increasing. Sigurjónsson \& Gunnlaugsson (1990) presented a rate of increase of 0.138 (annual rate $14.8 \%$ ) for humpbacks sighted off Iceland between 1968 and 1988. This rate is higher than probable, given the biological parameters of this species, however, for which a maximum potential growth rate of 0.126 (annual rate $13.4 \%$ ) has been presented (Clapham et al. 2000). Thus distributional shifts are likely to account
Fig. 1. Megaptera novaeangliae. Primary seasonal habitats in the North Atlantic Ocean. Individuals from all high-latitude summer feeding areas winter in the West Indies, but some individuals occur elsewhere in winter, notably off the Cape Verde Islands 
for some of this change. Barlow \& Clapham (1997) presented a rate of increase of 0.063 (annual rate $6.5 \%$ ) for humpback whales from the Gulf of Maine between 1979 and 1991 based on an inter-birth interval model. However, regional rates of increase are not necessarily representative of the broader population. Katona \& Beard (1990) presented estimates of abundance for the western North Atlantic between 1979 and 1986, and estimated an annual rate of increase of $9.9 \%$. However the precision of the estimate is low and this rate is not significantly different from zero. We present abundance estimates for North Atlantic humpback whales based upon capture-recapture techniques using naturally marked individuals identified over $14 \mathrm{yr}$ and estimate the rate of population increase.

\section{MATERIALS AND METHODS}

Individual identification. Individually distinctive natural markings on the ventral surface of the tail flukes allow identification of individual humpback whales (Katona et al. 1979). Two large collections of identification photographs exist covering extensive areas of the North Atlantic, the North Atlantic Humpback Whale Catalog (NAHWC), and the Years of the North Atlantic Humpback Whale (YoNAH) project. We used capture-recapture analyses of data from these 2 sources to estimate abundance.

The NAHWC is a central curation facility for fluke photographs collected throughout the North Atlantic, drawing upon directed research projects and opportunistic sightings. The collection primarily comprises photographs from the western North Atlantic (Katona \& Beard 1990). The NAHWC contains records of approximately 11500 sightings of approximately 5000 whales. Data used in these analyses were collected between 1979 and 1991. The YoNAH project was conducted during 1992 and 1993. YoNAH investigators collected individual identification photographs from all of the known major concentrations of humpback whales in the North Atlantic using protocols designed to minimize biases due to sampling (Smith et al. 1999). This collection contains approximately 4300 sightings of almost 3000 individual whales. A comparison between the NAHWC and YoNAH collections has not been conducted due to resource and time constraints. Thus estimates that require data from both collections could not be calculated.

Heterogeneity in capture probabilities and population definition. Heterogeneity of capture probabilities results in biases in capture-recapture abundance estimates (Pollock et al. 1990). This influences estimation of trends when the level of bias varies between estimates; the use of biased estimates may be acceptable in the estimation of trends provided the level of bias is consistent among all estimates used in the study.

As humpback whales are found in 2 quite distinct seasonal habitats, the photographs in each year form 2 distinct samples, one from the high-latitude summer feeding grounds, and the other from the low-latitude winter breeding grounds. Individual sampling probabilities are not uniform in either region, however the principal sources of heterogeneity in capture probabilities for humpback whales are different in the feeding and breeding grounds. To the extent that these sources of heterogeneity are independent, 2-sample Petersen estimates based on 1 feeding ground sample and 1 breeding ground sample should be relatively unbiased (Smith et al. 1999).

Heterogeneity in breeding ground samples is related to gender differences in behavior and migration (Brown et al. 1995, Palsbøll et al. 1997, Smith et al. 1999, Stevick et al. 2003), and estimates based upon 2 breeding ground samples have been shown to be negatively biased (Palsbøll et al. 1997, Smith et al. 1999). Few data are available for evaluating the gender ratios of individuals sampled in the principal North Atlantic breeding area in the West Indies prior to 1992. Differences in the probability of identifying individuals in different behavior classes on the breeding grounds (Smith et al. 1999) coupled with differences in habitat preference, site fidelity and migration between sexes (Craig \& Herman 1997, 2000, Dawbin 1997, Stevick et al. 2003), however, suggest that a consistent sex ratio across years is unlikely.

Heterogeneity in feeding ground samples is a function of individual site-fidelity and the distribution of effort relative to abundance (Hammond 1986, 1990, Smith et al. 1999). Substantial negative bias has been demonstrated in estimates using 2 feeding ground samples (Palsbøll et al. 1997, Smith et al. 1999). The spatial distribution and intensity of sampling in feeding areas is known to vary greatly between years, and this bias is unlikely to be consistent across samples. All estimates included here, therefore, utilize 1 feeding ground and 1 breeding ground sample.

Not all North Atlantic humpback whales winter in the West Indies. Some are known to winter in other regions, most notably in the Cape Verde Islands (Hazevoet \& Wenzel 2000). It has recently been shown that the proportion of resightings to the West Indies declines in eastern feeding areas (Stevick et al. 2003), suggesting that individuals from eastern feeding areas may be more likely to winter elsewhere. Small but significant differences have also been found in nuclear genetic markers between Iceland and other North Atlantic regions (Valsecchi et al. 1997), further suggesting a link between eastern feeding areas and individuals wintering outside the West Indies. 
If this were the case, it would result in whales summering in Iceland and Norway having a lower capture probability in both winter and summer, as some individuals from this area are not available to be sampled in the West Indies. Also, feeding ground sampling was not conducted in these areas in most years and was at a lower intensity than in most western feeding grounds when it was conducted (Table 1). Therefore, estimates for all combinations of years were made excluding the feeding ground samples from Icelandic and Norwegian waters. The estimates of abundance and the resulting trend thus represent the population of humpback whales that breeds in the West Indies. For 1992 and 1993 when more extensive sampling was conducted in Icelandic and Norwegian waters, an estimate was made using all feeding ground samples. This represents an ocean-basin-wide estimate. However, it is likely to be biased downwards to an unknown extent by the presence of individuals feeding in the east that winter in unsampled areas.

Small sample sizes. One difficulty in evaluating trends from these data is the variable and occasionally quite small samples, particularly from the West Indies. In many years, only 1 or 2 recaptures were made between successive sampling seasons. Small sample size contributes to low precision of the individual estimates, influencing the power of the analysis to detect trends (Gerrodette 1987), and may also result in bias in abundance estimates (Seber 1982).

The variability of estimates may be partially addressed by calculating means of several estimates, although these means may be strongly influenced by estimates of low precision or severe bias. Precisionbased weighting of means can account for variation in precision. In capture-recapture estimation, however,

Table 1. Megaptera novaeangliae. Number of individuals identified in each of 3 primary habitat areas in the North Atlantic during each of the sampling intervals that were used in abundance estimation

\begin{tabular}{|lrrc|}
\hline Years & \multicolumn{2}{c}{$\begin{array}{c}\text { Feeding area sample } \\
\text { Western }\end{array}$} & $\begin{array}{c}\text { Breeding } \\
\text { area sample }\end{array}$ \\
\hline $1979-80$ & 843 & 0 & 275 \\
$1980-81$ & 546 & 3 & 314 \\
$1981-82$ & 576 & 22 & 319 \\
$1982-83$ & 806 & 21 & 428 \\
$1983-84$ & 628 & 6 & 665 \\
$1984-85$ & 406 & 5 & 590 \\
$1985-86$ & 349 & 2 & 264 \\
$1986-87$ & 385 & 2 & 155 \\
$1987-88$ & 578 & 3 & 151 \\
$1988-89$ & 652 & 3 & 267 \\
$1989-90$ & 741 & 0 & 126 \\
$1990-91$ & 897 & 0 & 1317 \\
$1992-93$ & 1369 & 254 & \\
& & & \\
\hline
\end{tabular}

abundance and variance are estimated from the same data and are not independent, leading to negative bias in weighted means even if estimates are evenly distributed about their central tendency.

An alternative approach was applied here. Samples were pooled to increase sample sizes. To retain the feeding-breeding estimator, we pooled the feeding ground samples from 2 consecutive years and the breeding ground samples from 2 consecutive years.

This treatment eliminated much of the variability in estimates and improved the precision; the CVs for the pooled estimates are comparable to those from the means of 4 estimates based upon single-season samples from the same period. The bias due to lack of population closure is similar between these 2 approaches.

Pooling reduced the bias resulting from small sample sizes. Bias in Chapman's estimator is given as $b=\exp \left[-\left(n^{1}+1\right)\left(n^{2}+1\right) / N\right]$, though it has been shown that this bias is unlikely to exceed 0.02 if there are $\geq 7$ recaptures between samples (Seber 1982). Estimates of $b$ were calculated using the more conservative upper $95 \%$ confidence interval for our most precise estimate of abundance for the West Indies breeding population to represent $N$. These were very low for abundance estimates using pooled samples (median $6.1 \times 10^{-7}$; range $6.0 \times 10^{-77}$ to 0.011 ) compared with samples from single years (median 0.024 ; range $6.3 \times 10^{-9}$ to 0.55 ) Similarly, only 3 of $24(12.5 \%)$ estimates calculated using pooled samples were based upon fewer than 7 recaptures compared with 15 of 29 (52\%) estimates based upon sampling from single years.

Thus pooling of samples improves precision of estimates and reduces 1 potentially importance source of bias. As a result of these improvements, all estimates were calculated using pooled data.

Identification errors and photographic quality. The quality of images used in identification has been recognized as a potentially important source of bias in abundance estimates based on natural markings (Hammond 1986, Friday 1997). All photographs from 1992 and 1993 were coded for image quality using the criteria of Friday et al. (2000). For earlier years, only the best photograph from the breeding ground and the best from the feeding grounds each year were coded for quality due to time and resource limitations.

Abundance estimates were made using the modified Petersen estimator presented by Stevick et al. (2001) to account for identification errors. This correction is stratified by the distribution of photographic quality in the sample and the quality-specific error rates determined from comparison with genetic tagging (Stevick et al. 2001). Because multiple photographs of individuals in these samples were not coded for quality, the false negative error rate within each sample could not be calculated in the manner proposed by Stevick et al. 
(2001). Instead, this was calculated using the distribution of photographic qualities for unique individuals rather than for all photographs in a sample. This results in a slight underestimation of the true number of individuals identified during each sample, and thus a positive bias in the estimate of abundance. Error rates were calculated using both methods for the 1992 and 1993 samples for which all photographs were quality coded. These calculations indicated a difference in the estimated number of identified individuals of about $1.5 \%$ for feeding ground samples and $0.013 \%$ for breeding ground samples. Differences of this magnitude alter abundance estimates by less than $1 \%$.

Also, because the photographic quality was not determined for all sightings within a year, the analytical variance method was used rather than the parametric bootstrap (see Stevick et al. 2001). The analytical variance estimates were lower than the corresponding bootstrapped estimates (proportional bias 1.09 to 1.13) for estimates from 1992 and 1993 when both methods could be calculated.

Because the error correction may not fully account for bias in estimates using the poorest quality photographs, the mean square error (sum of bias squared and variance) was used to determine which minimal photographic quality was most appropriate to use for optimal balance of bias and precision. Bias was determined as the difference between an estimate and the abundance estimated from data restricted to good photographic quality $(\leq 2)$. This was deemed to be the closest approximation of an unbiased estimate; estimates from only excellent quality photographs $(=1)$ that should in theory be least biased have low sample size and may suffer from the related bias (Friday 1997).

To determine the quality of photographs to include in abundance estimation, 5 abundance estimates were generated for 1992 and 1993 utilizing all feeding ground samples and different minimum acceptable photographic qualities (Table 2). Because photo-

Table 2. Megaptera novaeangliae. Estimates of abundance, $\mathrm{N}$, for 1992 to 1993 calculated using different minimum levels of photographic quality. Photographic qualities (PQ) 1 and 2: excellent and good photographs respectively; 3: poor photographs, but with information content largely retained; 4 : photographs in which information is compromised by photographic quality; L, R: photographs showing only left or right halves of flukes respectively; MSE: mean square error

\begin{tabular}{|lrrrr|}
\hline PQ & N & SE & CV & MSE \\
\hline 1,2 & 10869 & 1066.91 & 0.0976 & 1138297 \\
$1,2,3$ & 10544 & 810.02 & 0.0766 & 656456 \\
$1,2,3,4$ & 11573 & 807.68 & 0.0692 & 653051 \\
$1,2,3,4, \mathrm{~L}$ & 12104 & 864.86 & 0.0704 & 749223 \\
$1,2,3,4, \mathrm{R}$ & 12034 & 840.95 & 0.0687 & 708355 \\
\hline
\end{tabular}

graphic quality was known for all sightings during these years, each of these 5 estimates were made using the full error-corrected estimator and the bootstrap estimate of variance. The estimate based upon all photographs showing whole flukes (Photographic Qualities 1, 2, 3 and 4: Table 2) but excluding photographs showing only the right or left half of the flukes (L and R: Table 2) had the lowest mean square error. Thus all estimates used in these analyses were calculated using whole fluke photographs of all qualities. The number of samples used for abundance estimation are presented in Table 1.

Rate of increase. An exponential growth model was fitted to the abundance estimates. In this model, the intrinsic rate of increase, $r$, in the population, $N$, is constant over time, $t: N_{t}=N_{0} \mathrm{e}^{r t}$. To investigate the possibility of a change in population growth rate, a logistic model was also fitted (Hastings 1997). To account for variability in the precision of abundance estimates, estimates were weighted by the inverse of the $\mathrm{CV}^{2}$. This gives a measure of precision that is less strongly correlated with abundance than is the variance, and thus less likely to bias the regression toward low estimates. The fit of the 2 models was compared using the second-order bias adjustment to Akaike's information criterion $\left(\mathrm{AIC}_{\mathrm{c}}\right)$ (Burnham \& Anderson 1998).

\section{RESULTS}

\section{Abundance estimates for West Indies breeding population}

A total of 24 estimates was calculated for individuals wintering in the West Indies (Table 3). Estimates ranged from 5930 to 12580 individuals with CVs from 0.07 to 0.39 .

Four consecutive estimates were anomalously lower than any adjacent estimates (Table 3). Values this extreme seem improbable given the precision of the estimates. To examine this, the other estimates were log-transformed and an unweighted linear regression was used to calculate expected values for these years. Given the observed values and standard errors for these 4 estimates and assuming a lognormal distribution, the probabilities of obtaining these expected values were all $<0.0001$.

Stevick et al. $(1999,2003)$ showed that the date of sighting in the West Indies is related, in part, to highlatitude origin; humpback whales from the eastern North Atlantic were seen in the West Indies significantly later than those from the west. Only 1 individual from Norwegian waters was identified in the West Indies prior to February 19 (Stevick et al. 1999). This 
Table 3. Megaptera novaeangliae. Estimates of abundance, $\mathrm{N}$, for North Atlantic humpback whales from West Indies breeding population

\begin{tabular}{|lrrrr|}
\hline \multicolumn{3}{|c}{ Years } & \multicolumn{3}{c|}{ Corrected estimates } \\
Feeding & Breeding & $\mathrm{N}$ & SE & CV\% \\
\hline $1979-80$ & $1979-80$ & 7260 & 1177 & 16.2 \\
$1979-80$ & $1980-81$ & 6918 & 1020 & 14.7 \\
$1980-81$ & $1980-81$ & 9439 & 2078 & 22.0 \\
$1980-81$ & $1981-82$ & 8119 & 1639 & 20.2 \\
$1981-82$ & $1981-82$ & 7234 & 1330 & 18.4 \\
$1981-82$ & $1982-83$ & 9695 & 1801 & 18.6 \\
$1982-83$ & $1982-83$ & 8864 & 1313 & 14.8 \\
$1982-83$ & $1983-84$ & 7064 & 727 & 10.3 \\
$1983-84$ & $1983-84$ & 7603 & 934 & 12.3 \\
$1983-84$ & $1984-85$ & 7309 & 938 & 12.8 \\
$1984-85$ & $1984-85$ & 9200 & 1696 & 18.4 \\
$1984-85$ & $1985-86$ & 9948 & 2832 & 28.5 \\
$1985-86$ & $1985-86$ & 10310 & 3238 & 31.4 \\
$1985-86$ & $1986-87$ & 8100 & 2886 & 35.6 \\
$1986-87$ & $1986-87$ & 11185 & 4377 & 39.1 \\
$1986-87$ & $1987-88$ & 9083 & 3720 & 36.0 \\
$1987-88$ & $1987-88$ & 10297 & 3251 & 31.6 \\
$1987-88$ & $1988-89$ & 11144 & 2809 & 25.2 \\
$1988-89$ & $1988-89$ & 12582 & 3177 & 25.2 \\
$1988-89$ & $1989-90$ & $7403^{\mathrm{a}}$ & 1527 & 20.6 \\
$1989-90$ & $1989-90$ & $8442^{\mathrm{a}}$ & 1746 & 20.7 \\
$1989-90$ & $1990-91$ & $5927^{\mathrm{a}}$ & 1349 & 22.8 \\
$1990-91$ & $1990-91$ & $8330^{\mathrm{a}}$ & 2056 & 24.7 \\
$1992-93$ & $1992-93$ & 10752 & 736 & 6.8 \\
${ }^{\mathrm{a}}$ See Appendix 1 for discussion of these 4 & anomalous \\
estimates & & & & \\
& & & & \\
\hline
\end{tabular}

introduces a possible source of heterogeneity in capture probabilities that is common to the feeding and the breeding ground samples, and thus a source of bias in abundance estimates using the feeding-breeding estimator.

A resampling exercise was conducted to assess this bias (Appendix 1). The results demonstrate that the bias observed in these estimates is consistent with West Indies sampling during 1989 to 1991, being restricted to the very early winter when few individuals from the eastern regions were present, and show little evidence for a similar effect on any other estimates. Thus the 4 estimates that use the 1989 and 1990 and the 1990 and 1991 West Indies samples were not used in calculating the rate of increase.

\section{Abundance estimate for North Atlantic Ocean}

For 1992 and 1993 abundance was estimated (using all feeding ground samples) as 11570 (95\% CI = 10290 to 13390 ). This estimate encompasses the entire North Atlantic Ocean, since individuals from all of the summer feeding grounds visit the West Indies in winter. The existence of humpback whales in winter outside the West Indies will produce bias in this estimate, however, as shown above. As few data are available on the proportion of individuals that might winter outside the West Indies and the relationship of these individuals to those from the West Indies, bias resulting from the lack of sampling in the other wintering area(s) cannot currently be quantified.

\section{Trends in abundance}

The instantaneous rate of increase, $r$, was estimated to be 0.0311 ( $\mathrm{SE}=0.0052$; corrected $\mathrm{r}^{2}=0.66$ ) equivalent to an annual rate of $3.15 \%$ (Fig. 2). If this rate of increase had been constant since hunting ended in 1955 , the population at that time, $N_{0}$, would have been about 3400 . The logistic model produced an estimate of $r=0.0788\left(\mathrm{SE}=0.117 ;\right.$ corrected $\left.\mathrm{r}^{2}=0.66\right)$. This model suggests that abundance in 1955, $N_{0}$, was about 1700 with a carrying capacity, $K$, of about 15500 (Fig. 2). The lower $\mathrm{AIC}_{\mathrm{c}}$ value is for exponential growth, and the difference in AIC values is relatively small $\left(\Delta \mathrm{AIC}_{\mathrm{C}}=2.7\right)$.

Two factors introduce uncertainty into the estimated variance of the abundance estimates: (1) the use of analytical estimator for variance, and (2) the calculation of the false negative error rate by individual rather than by sample. In a weighted regression these factors may, in turn, influence the estimate of trend. To investigate the sensitivity of the trend estimate to this uncertainty, a simple simulation was conducted. The variance of each estimate was increased by a proportional

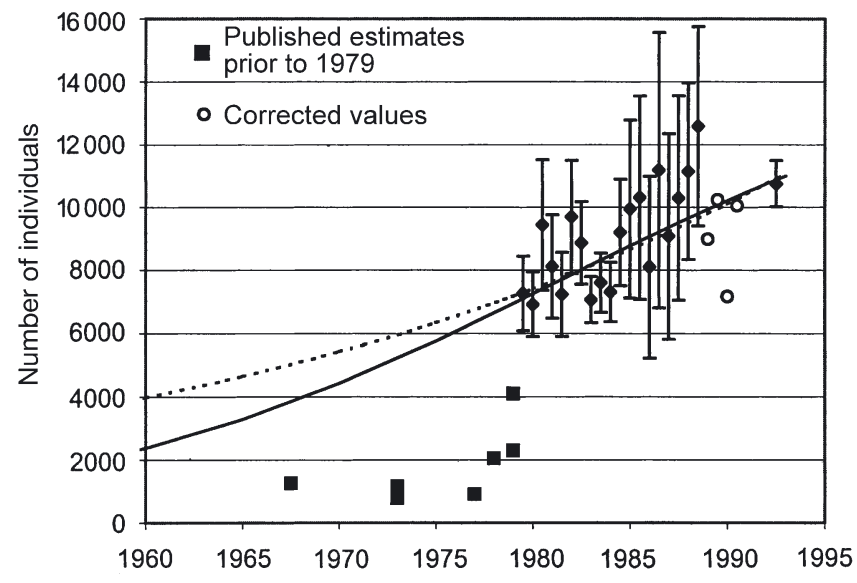

Fig. 2. Megaptera novaeangliae. Abundance estimates $( \pm \mathrm{SE})$ for humpback whales wintering in the West Indies with exponential $(\cdots \cdot)$ and logistic $(-)$ population growth models fitted. Approximate corrected values for estimates showing severe bias (see Appendix 1). These estimates are not used in fitting the regression. Previously published estimates of abundance all fall well below the expected values from either model 
factor selected at random from a normal distribution, estimates and variances were log-transformed, and the standard error of the slopes of the resulting inversevariance-weighted linear regressions was calculated over 1000 replicates. For variances increased by a mean proportion of $0.1(\mathrm{SD}=0.05)$, the standard error of the resulting slopes was only $1.40 \times 10^{-4}$. Doubling the mean and standard deviation of the proportional increase, changed the standard error only slightly to $1.46 \times 10^{-4}$, while a mean proportional increase in variance of $0.5(\mathrm{SD}=0.2)$ only resulted in a standard error of $4.53 \times 10^{-4}$, suggesting that these factors have little influence on the estimation of trends from these data.

Additionally, because consecutive abundance estimates utilize common data, these estimates are potentially correlated. While such autocorrelation is unlikely to influence the estimated trend, the estimated variance of the trend will be artificially low. Investigation of the 23 estimates for which data overlap shows no evidence for significant autocorrelation at the 0.05 level (Durbin-Watson $d=1.501$ ). Inclusion of the 1992 and 1993 estimate based upon independent data would further weaken any effect on the variance from serial autocorrelation.

\section{DISCUSSION}

\section{Comparison with previous results}

Previously published abundance estimates for humpback whales in the North Atlantic suggest a lower abundance but a greater rate of increase than that documented here. Smith et al. (1999) published an estimate of 10600 (95\% CI = 9300-12 100) for the period 1992 to 1993 using essentially the same data from the YoNAH project as those used here. While the confidence intervals of these estimates widely overlap, our estimate is based on several methodological improvements. The use of pooled samples here results in larger sample sizes and eliminates the bias due to inverse variance weighting. Additionally, corrections to account for errors in identification have improved the estimate and allowed for inclusion of additional data. Thus although the estimate is biased due to violation of the closed population assumption (see following subsection), and is probably also biased due to the presence of an unsampled wintering area, it provides the best available estimate of abundance for humpback whales in the North Atlantic Ocean.

Katona \& Beard (1990) estimated humpback whale abundance at $5505( \pm 2617,95 \%$ CI $)$ for the period 1979 to 1986 using data from the NAHWC. The midpoint covered by their estimate is 1982 to 83,10 yr prior to that in the study of Smith et al. (1999). The rate of increase based on these 2 estimates over the $10 \mathrm{yr}$ period is thus 0.0655 (annual rate $6.8 \%$ ). However, the data used in the analysis of Katana \& Beard (1990) contained very few individuals from Icelandic or Norwegian waters and thus represented almost exclusively the West Indies breeding group, while the data analyzed by Smith et al. (1999) included a substantial Icelandic and Norwegian sample, making a direct comparison between these 2 estimates problematic.

Additionally, the Katona \& Beard (1990) estimate was calculated in such a manner that variance was accounted for twice and so was maximally influenced by the lack of independence between abundance and variance. For each year, 3 estimates were calculated, 1 based only on whole flukes, 1 comprising whole and left halves, and 1 comprising whole and right halves. The estimate with the lowest standard error was selected for each year. The variance weighted mean was then calculated from the selected estimates. Using data from their Table 5, but consistently using photographs of whole flukes and not weighting the mean, yields an estimate of 7837; this is comparable to the estimates calculated here for the same time period.

Several previously published estimates of abundance based on transect surveys are available for the West Indies breeding population or the western North Atlantic (Fig. 2). While it is tempting to use these estimates to examine population growth prior to 1979 , all the transect-survey-based estimates are well below the trend suggested by either the exponential or logistic models. These estimates were made using substantially different methodologies, and the results are not comparable with those presented here. The lower estimates could result from violation of model assumptions during those surveys (Buckland et al. 1993). Alternatively, these may represent relatively unbiased estimates of abundance in the area surveyed during the study period, while these may not correspond to the overall population because of spatial and temporal patterns of habitat use. In either case, use of these estimates to assess trends would artificially inflate estimates of population growth rates.

\section{Open population bias}

All these abundance estimates are subject to bias due to lack of population closure. Both recruitment and mortality occur between samples. Hammond (1986) showed that Petersen abundance estimates for a population subject to both death and recruitment were positively biased for population size at the time of the first sample by approximately the recruitment rate divided by the survival probability. 
For the North Atlantic humpback whale population, 2 estimates of survival rate are available; both are based upon resighting results from the Gulf of Maine. Buckland (1990) estimated a survival rate of 0.951 (SE $=0.010)$, while Barlow \& Clapham (1997) using an expanded version of the same database estimated a survival rate of non-calves of 0.960 (SE $=0.008$ ). Utilizing the rate of increase calculated here, and applying the rate of bias indicated by Hammond (1986) suggests that the abundance estimates presented here are positively biased by between 3.5 and $4 \%$.

Pooling of samples over 2 yr implies that the population is subject to mortality and natality during a sampling period as well. Simulations based upon YoNAH sampling subject to mortality and recruitment show that the lack of population closure during sampling periods has little effect; the bias in pooled-sample estimates is about $0.2 \%$ larger than that for the corresponding estimate using means (Friday et al. 2001). This similarity is to be expected because the mean time elapsed between samples was 6 mo in both cases.

\section{Pre-exploitation abundance and recovery}

North Atlantic humpback whales have had the longest time to recover from exploitation of any population of this species, with limited hunting since the 1920s and protection since 1955. However, other potential threats have been identified that might impede population recovery (NMFS 1991), and data with which to document recovery or the rate of increase have been limited. The data presented here result from a unique large-scale, long-term collaboration. This allows unprecedented opportunity to estimate the abundance and rate of increase of humpback whales over an extensive geographic region. The resulting abundance estimates are larger and more precise than those previously presented for this population, and show that abundance is increasing.

The estimated annual growth rate from the exponential model is rather low given the reproductive potential and estimated survival rates of humpback whales (Clapham et al. 2000). This may be an indication that the rate of population change is slowing as the population approaches carrying capacity, or it could reflect current stresses on the population. The data do not support the additional parameter for the logistic model. There is little shape to the curve and the lowest sampling intensity occurred during the middle years of the study, confounding efforts to compare these relationships. Thus we conclude that these data are insufficient to determine whether the population is continuing to grow at an exponential rate, or if the growth rate is slowing.
It is also unclear how this most recent estimate of abundance compares to pre-exploitation population size and thus the extent of recovery. With an estimated 29279 individuals taken since 1664, the total estimated historic take is nearly 3 times the best estimate of current abundance presented here, and it has further been estimated that in excess of 5000 individuals were killed in a single $10 \mathrm{yr}$ period spanning the turn of the 20th century (Smith \& Reeves 2003b). Both these factors suggest a large pre-exploitation abundance. The documented catch history in the North Atlantic spans more than $300 \mathrm{yr}$, however. The fishery operated at highly variable intensity throughout this period (Fig. 3), and shifted geographically over time (Reeves \& Smith 2002, Smith \& Reeves 2003b). Protracted catches at low levels may result in large cumulative catches yet have minimal impact on abundance. If these same catches are concentrated on specific subunits of the population, however, the regional effects may be devastating and recovery slow.

Humpbacks were depleted by such an early date that catch records from many areas are incomplete or absent, complicating interpretation of catch data. Illegal and unreported catches contribute to the uncertainty in estimates of pre-exploitation abundance based upon reported catches. It is likely that noncompliance with International Whaling Commission catch and reporting regulations was widespread, and fleets under several flags operated outside the Commission altogether (Mackintosh 1965, Tønnessen \& Johnsen 1982, Yablokov 1994). Yablokov et al. (1998) stated that 'Soviet whaling fleets... used to begin hunting whales immediately after passing the Suez Channel (sic), Gibraltar, and exiting from European coastal waters' (emphasis added). Thus, while no evidence has been presented suggesting extensive undocumented takes of humpback whales in the North Atlantic, these may have occurred by whaling fleets

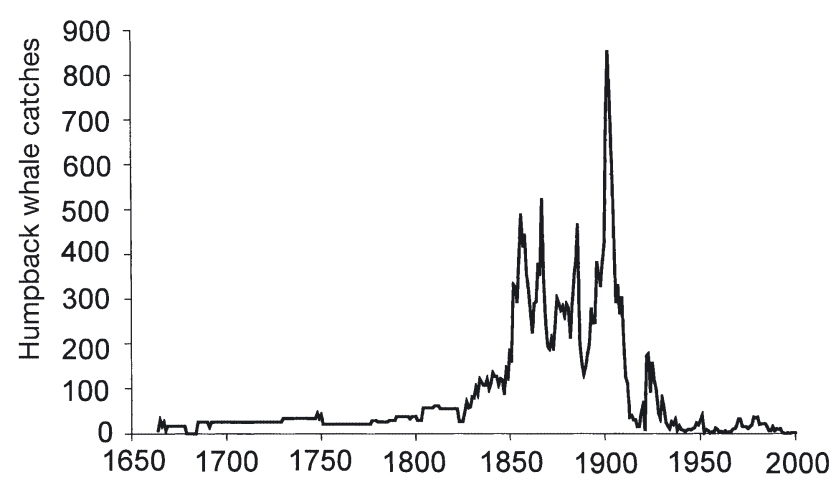

Fig. 3. Megaptera novaeangliae. Estimated annual catches of humpback whales from North Atlantic Ocean 1664 to 2000. Data include individuals caught incidentally through entanglement in fishing nets (from Smith \& Reeves 2003b) 
bound for the Southern Hemisphere at least until 1972, when an international inspection program was implemented.

The results presented here are strongly indicative of a substantial recovery of humpback whales in the North Atlantic following the end of commercial hunting. Lack of ability to distinguish between models of population growth and uncertainties regarding preexploitation abundance confound any definitive conclusions regarding the relationship between current abundance and either historic levels of abundance or the potential for further population growth.

Acknowledgements. Over 350 individuals, institutions or groups contributed the identification photographs that made these analyses possible. We cannot thank them enough. For patient, careful and critical photographic comparison we wish to thank L. Baraff, L. Barnes, M. Crone, T. Fernald, P. Harcourt, S. Hayward, J. Jensen, S. Kraus, S. Martin, G. McCullough, D. Morin, P. Olsen, J. Perkins, J. Rock, R. Seton, N. Stevick, G. Stone, K. VanDine, F. Wenzel, the many other staff and volunteers at the College of the Atlantic who assisted in this work, and particularly the many students who contributed time and energy to this project. Quality coding of photographs was principally conducted by T. Fernald and O. Uz. Critical reading of this manuscript by S. Buckland, D. DenDanto, F. Serchuk, H. Whitehead and 4 anonymous reviewers substantially improved the analysis and presentation. M. Bravington and M. Kingsley provided information on autocorrelation. Fig. 1 was prepared by T. Johnson, College of the Atlantic GIS Laboratory. Portions of Fig. 1 include intellectual property of ESRI and its licensor(s) and are used under license. Principal financial support for photographic analysis is provided by continuing contracts from the United States National Marine Fisheries Service (NMFS) to the College of the Atlantic. Additional support during the YoNAH photographic comparison was provided by the United States Marine Mammal Commission. Support for this analysis was provided by the Wm E. Anderson Trust and by NMFS under contract \#40ESNF900044 to P.T.S.

\section{LITERATURE CITED}

Bannister JL (1994) Continued increase in humpback whales off Western Australia. Rep Int Whal Comm 44:309-310

Barlow J, Clapham PJ (1997) A new birth-interval approach to estimating demographic parameters of humpback whales. Ecology 78:535-546

Best PB (1993) Increase rates in severely depleted stocks of baleen whales. ICES J Mar Sci 50:169-186

Brown MR, Corkeron PJ, Hale PT, Schultz KW, Bryden MM (1995) Evidence for a sex-segregated migration in the humpback whale (Megaptera novaeangliae). Proc R Soc Lond Ser B 259:229-234

Buckland ST (1990) Estimation of survival rates from sightings of individually identifiable whales. Rep Int Whal Comm Special Issue 12:149-153

Buckland ST, Anderson DR, Burnham KP, Laake JL (1993) Distance sampling. Chapman \& Hall, London

Burnham KP, Anderson DR (1998) Model selection and inference: a practical information-theoretic approach. Springer-Verlag, New York

Clapham PJ, Robbins J, Brown M, Wade PR, Findlay KP
(2000) A note on probable rates of population growth in humpback whales. Paper SC/52 Appendix 5, 52nd Meet Int Whal Comm. International Whaling Commission, Impington, Cambridge

Craig AS, Herman LM (1997) Sex differences in site fidelity and migration of humpback whales (Megaptera novaeangliae) to the Hawaiian Islands. Can J Zool 75:1923-1933

Craig AS, Herman LM (2000) Habitat preferences of female humpback whales Megaptera novaeangliae in the Hawaiian Islands are associated with reproductive status. Mar Ecol Prog Ser 193:209-216

Dawbin WH (1997) Temporal segregation of humpback whales during migration in southern hemisphere waters. Mem Queensl Mus 42:105-138

Friday N (1997) Evaluating photographic capture-recapture estimates of abundance of North Atlantic humpback whales. PhD thesis, University of Rhode Island, Kingston, RI

Friday N, Smith TD, Stevick PT, Allen J (2000) Measurement of photographic quality and animal distinctiveness for the photographic identification of humpback whales. Mar Mamm Sci 16:355-374

Friday N, Smith TD, Hammond PS, Robbins J, Mattila DK (2001) Modeling the effects of behaviour and population dynamics on capture-recapture estimates of abundance of humpback whales. Document SC/53/NAH14 presented to the IWC Scientific Committee July 2001. International Whaling Commission, Impington, Cambridge

Gerrodette T (1987) A power analysis for detecting trends. Ecology 68:1364-1372

Hammond PS (1986) Estimating the size of naturally marked whale populations using capture-recapture techniques. Rep Int Whal Comm Special Issue 8:253-282

Hammond PS (1990) Heterogeneity in the Gulf of Maine? Estimating humpback whale population size when capture probabilities are not equal. Rep Int Whal Comm Special Issue 12:135-139

Hastings A (1997) Population biology: concepts and models. Springer-Verlag, New York

Hazevoet CJ, Wenzel FW (2000) Whales and dolphins (Mammalia, Cetacea) of the Cape Verde Islands, with special reference to the humpback whale Megaptera novaeangliae (Borowski, 1781). Contrib Zool 69:197-211

Ingebrigtsen A (1929) Whales caught in the North Atlantic and other seas. Rapp P-V Réun Cons Int Explor Mer 56:1-26

IUCN (International Union for Conservation of Nature and Natural Resources) (2000) 2000 IUCN red list of threatened species. World Conservation Union, Gland, Switzerland (available at www.redlist.org)

Katona SK, Beard JA (1990) Population size, migrations and feeding aggregations of the humpback whale (Megaptera novaeangliae) in the western North Atlantic Ocean. Rep Int Whal Comm Special Issue 12:295-305

Katona SK, Baxter B, Brazier O, Kraus S, Perkins J, Whitehead $\mathrm{H}$ (1979) Identification of humpback whales by fluke photographs. In: Winn HE, Olla BL (eds) The behavior of marine animals. Vol 3, Cetacea. Plenum Press, New York, p 33-44

Mackintosh NA (1965) The stocks of whales. Fishing News (Books) London

Moore MJ, Berrow SD, Jensen BA, Carr P, Sears R, Rowntree VJ, Payne R, Hamilton PK (1999) Relative abundance of large whales around South Georgia (1979-1998). Mar Mamm Sci 15:1287-1302

NMFS (National Marine Fisheries Service) (1991) Recovery plan for the humpback whale (Megaptera novaeangliae). National Marine Fisheries Service (NMFS) Silver Springs, MD 
Palsbøll PJ, Allen J, Bérubé M, Clapham PJ and 15 others (1997) Genetic tagging of humpback whales. Nature 388: 767-769

Paterson R, Paterson P, Cato DH (2001) Status of humpback whales, Megaptera novaeangliae, in East Australia at the end of the 20th century. Mem Queensl Mus 47:579-586

Pollock KH, Nichols JD, Brownie C, Hines JE (1990) Statistical inference for capture-recapture experiments. Wildl Monogr 107:1-97

Reeves RR, Smith TD (2002) Historical catches of humpback whales in the North Atlantic Ocean: an overview of sources. J Cetacean Res Manag 4:219-234

Seber GAF (1982) The estimation of animal abundance and related parameters. Charles Griffin, London

Sigurjónsson J (1988) Operational factors of the Icelandic large whale fishery. Rep Int Whal Comm 38:327-333

Sigurjónsson J, Gunnlaugsson T (1990) Recent trends in abundance of blue (Balaenoptera musculus) and humpback whales (Megaptera novaeangliae) off west and southwest Iceland with a note on the occurrence of other cetacean species. Rep Int Whal Comm 40:537-551

Smith TD, Reeves RR (2002) Estimating historical humpback removals from the North Atlantic. J Cetacean Res Manag 4 (Suppl):242-255

Smith TD, Reeves RR (2003a) Estimating American 19th century catches of humpback whales in the West Indies and Cape Verde Islands. Caribb J Sci (in press)

Smith TD, Reeves RR (2003b) Estimating historic humpback removals from the North Atlantic: an update. J Cetacean Res Manag 5 (Suppl) (in press)
Smith TD, Allen J, Clapham PJ, Hammond PS and 8 others (1999) An ocean-basin-wide mark-recapture study of the North Atlantic humpback whale (Megaptera novaeangliae). Mar Mamm Sci 15:1-32

Stevick PT, Øien N, Mattila DK (1999) Migratory destinations of humpback whales from Norwegian and adjacent waters: evidence for stock identity. J Cetacean Res Manag 1:147-152

Stevick PT, Palsbøll PJ, Smith TD, Bravington MV, Hammond PS (2001) Errors in identification using natural markings: rates, sources, and effects on capture-recapture estimates of abundance. Can J Fish Aquat Sci 58:1861-1870

Stevick PT, Allen J, Bérubé M, Clapham PJ and 10 others (2003) Segregation of migration by feeding ground origin in North Atlantic humpback whales (Megaptera novaeangliae). J Zool 259:231-237

Thompson DAW (1928) On whales landed at the Scottish whaling stations during the years 1908-1914 and 1920-1927. Sci Fish Board Scotl 3:1-40

Tønnessen JN, Johnsen AO (1982) The history of modern whaling. C. Hurst, London

Valsecchi E, Palsbøll PJ, Hale P, Glockner-Ferrari DA and 9 others (1997) Microsatellite genetic distances between oceanic populations of the humpback whale (Megaptera novaeangliae). Mol Biol Evol 14:355-362

Yablokov AV (1994) Validity of whaling data. Nature (Lond) $367: 108$

Yablokov AV, Zemsky VA, Mikhalev YA, Tormosov VV, Berzin AA (1998) Data on Soviet whaling in the Antarctic in 1947-1972 (population aspects). Russ J Ecol 29:38-42 
Appendix 1. Megaptera novaeangliae. Correction of abundance estimates

Of the abundance estimates, 4 were well below that of the overall trend. Of these, 2 estimates used the 1990 to 1991 winter sample; the other 2 used the 1989 to 1990 winter sample. Sampling in winter of these years was conducted earlier than in any other winters during the study; during 1990 and 1991 no sampling was conducted after February 18, while for the 1989 to 1990 sample only $26 \%$ of individuals were sampled after this date and less than $10 \%$ after February 25. In contrast, no other winter sample had less than $30 \%$ of whales identified later than February 18. Because of segregation in migration timing by feeding ground origin (Stevick et al. 2003), individuals from the eastern North Atlantic are likely to be substantially underrepresented in the winter samples for all 4 of these estimates. As no photographs were obtained from Iceland or Norway during this period, eastern whales are also under-represented in the summer sample. This heterogeneity in capture probabilities may result in low estimates for these years.

To investigate the relationship between sighting dates in the West Indies and abundance estimates, the mean sighting dates in the West Indies were calculated for each estimate and plotted against the residual from trend estimation. Residuals were based on unweighted regression excluding the 4 estimates under investigation. There was no obvious relationship between abundance estimates and the mean sampling dates for the West Indies sample on which they were based, with the notable exception of the 4 anomalous estimates outlined above; these were based upon the earliest West Indies samples and had the largest residuals (Fig. A1). The correlation for the remaining points was not significant $\left(\mathrm{r}_{18}=-0.229\right)$.

To further examine the relationship between sighting date and recapture rate, random samples of 200 individuals each were selected from the 1992 and 1993 West Indies sample. These years were used because of the large sample size and coverage over much of the West Indies season. Feeding ground recaptures from Iceland and Norway were excluded to more closely approximate high-latitude sampling for years preceding 1992. The number of individuals with feeding ground records was compiled for each replicate.

The relationship between the number of recaptures and mean West Indies dates is weak but significant; there was considerable variability in the number of individuals resighted across the range of mean dates $\left(\mathrm{r}_{198}=-0.210, \mathrm{p}<\right.$ $0.01)$.
Because of this low correlation when sampling occurred throughout the season, we compared the number of recaptures between samples selected from all West Indies dates and samples selected only from those collected prior to February 19. In contrast to the weak relationship for sampling over the entire season, a strong, highly significant relationship was observed. A mean of 4.84 more recaptures occurred in the early samples than in those taken across the entire season (Student's $t=7.59, \mathrm{p}=1.2 \times 10^{-12}$ ). Thus the number of re-captures is biased upward (proportional bias 1.23) if samples are collected only early in the breeding season and there is no sampling in Iceland and Norway. When this bias is applied to the number of recaptures observed during the 1989 to 1991 period and Chapman's estimators calculated, 3 of the 4 bias-corrected estimates fall approximately where predicted by the regression, while 1 remains substantially low (Fig. 2).

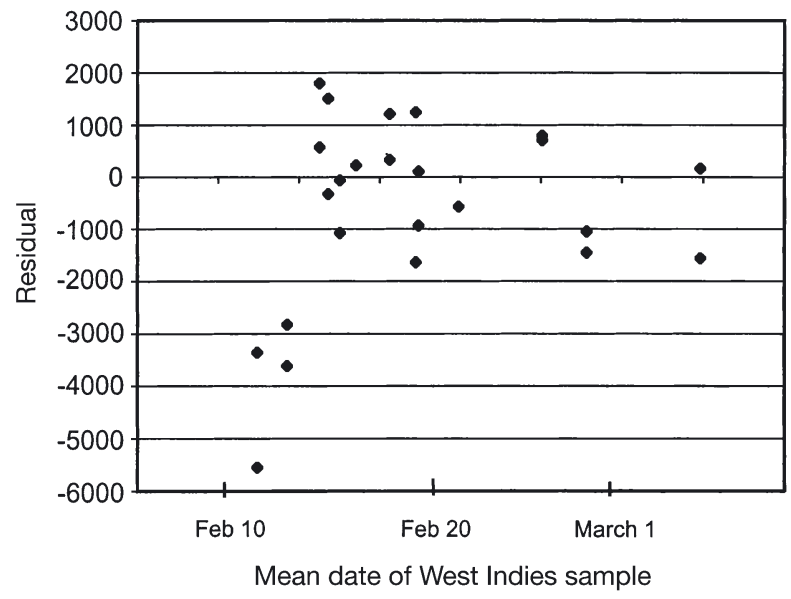

Fig. A1. Megaptera novaeangliae. Bias in abundance estimates related to time of sampling in West Indies. Relationship between residual for abundance estimates of North Atlantic humpback whales and mean date of West Indies sample used in calculating estimates shows that the 4 estimates for the West Indies sample collected earliest in the season are substantially lower than expected. Little pattern is evident in remaining residuals 